required to establish whether this finding is generic across the UK and the underlying mechanisms driving this phenomenon.
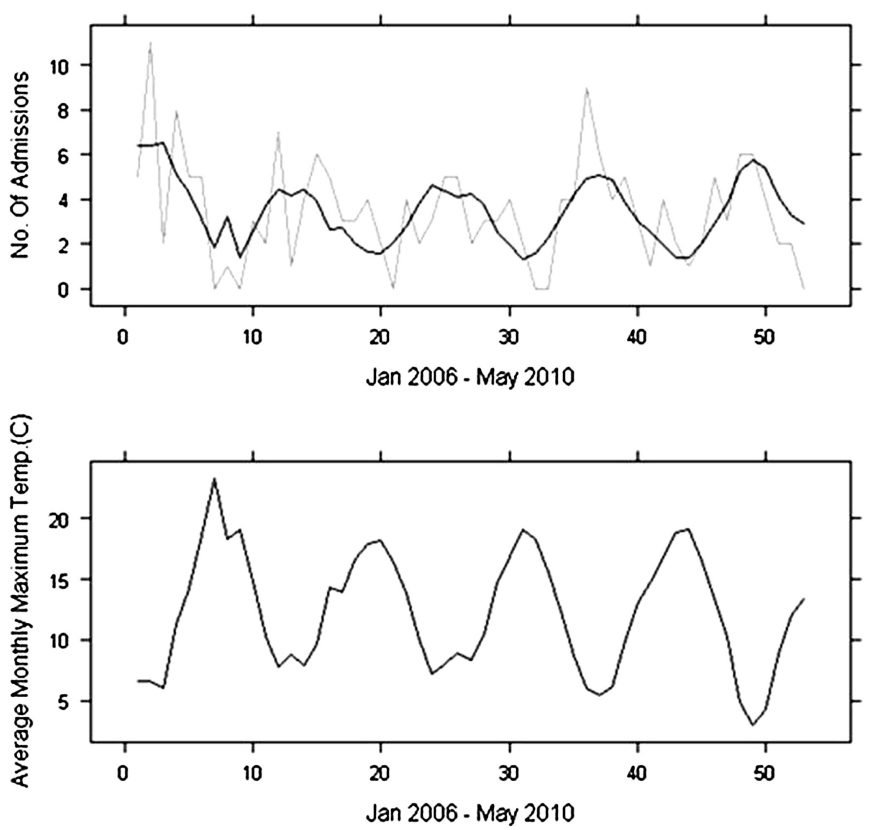

Abstract P81 Figure 1 Variation in monthly admissions of children with empyema and variation in mean monthly maximum temperature from January 2006-May 2010. 1st plot: Grey line-observed number of admissions, Black line-admissions predicted by model.

\section{P82 WHAT IS THE ROLE OF CHEST COMPUTED TOMOGRAPHY IN CHILDREN WITH PARAPNEUMONIC EFFUSION?}

doi:10.1136/thx.2010.150979.33

A Parmar, G Peek, R Firmin, H Pandya, E Gaillard. University Hospitals Leicester NHS Trust, Leicester, England

Introduction The incidence of parapneumonic effusion in children has been rising in the UK since the mid 1990s (1). There is anecdotal evidence that the number of complicated cases with more severe illness may be increasing. This is frequently due to severe underlying, often necrotic pneumonia, caused by unusual organisms (2), pulmonary abscesses or bronchopleural fistulas. Chest ultrasound does not reliably identify these processes and CT scanning is the investigation of choice. However, there has been little research in the use of chest CT in children with parapneumonic effusion and its use remains controversial.

Aims To evaluate the usefulness of chest CT in children with parapneumonic effusion.

Methods We retrospectively reviewed the medical notes and imaging of all children admitted between January 2004 and December 2009 with a diagnosis of parapneumonic effusion to the University Hospitals of Leicester NHS Trust.

Results A total of 183 children were identified. Of this number, 51 children underwent CT scanning. The main indications for chest CT were as follows: slow/no response to IV antibiotic treatment (25\%), failed attempt at chest drainage without urokinase (24\%) and acute critical clinical deterioration (16\%). Other indications included failure of chest drainage with urokinase, failure of surgical intervention or investigation for other pathology. A range of pathological findings were identified with CT. $38 \%$ of the CT scans identified collapse consolidation. Other pathology was also identified that was not apparent on ultrasound scan. $4 \%$ identified pulmonary abscess,
$4 \%$ identified areas of lung necrosis, $4 \%$ identified broncho-pleural fistula and $6 \%$ identified cavitating pneumonias.

Conclusion (1) A chest CT is useful in children with a complicated parapneumonic effusion to detect lung pathology not readily detected with chest ultrasound. (2) A small number of children have a pulmonary abscess complicating the parapneumonic effusion. (3) Further research is needed to establish the role and timing of chest CT scanning in children with infective pleural disease.

\section{REFERENCES}

1. BTS Standards of Care Committee. BTS guidelines for the management of pleural infection in children. Thorax 2005:60(Suppl I):i1-21.

2. Thomas B, Pugalenthi A, Chilvers M. Pleuropulmonary complications of PVL-positive Staphylococcus aureus infection in children. Acta Paediatr 2009;98:1372-5.

\section{Respiratory education and training issues P83 VALIDATION OF A NOVEL PORCINE-RESIN THORAX MODEL FOR CHEST DRAIN INSERTION TRAINING}

doi:10.1136/thx.2010.150979.34

T R Naicker, E A Hughes, D T McLeod. Sandwell General Hospital, Birmingham, UK

Objective Our poster at the 2009 winter BTS meeting described the Chest drain training module for CMT1 and CMT2 trainees in West Midlands Deanery. We have proceeded further to formally validate our novel Porcine-Resin thorax model for Chest drain insertion training by assessing the face, content, and construct validity of the model.

Methods We recruited 82 doctors who work in General Medicine and Allied Specialties in Hospitals across West Midlands Deanery in UK. They were further divided into three groups as novice, intermediate and expert depending on the number of chest drains they had performed previously. During the study, they were asked to insert a chest drain using seldinger technique in the Porcine-Resin thorax model and their performance was recorded and marked anonymously using checklist scoring system. We developed the model using porcine ribs mounted on a resin cast of human thorax. All participants completed a questionnaire regarding the realism of the simulator after they completed $2 \mathrm{~h}$ of training and updated their skills using the model. In addition, the intermediate and expert groups also have given their views regarding the appropriateness of the simulator for training and assessment purposes.

Results The expert group performed better than the intermediate group ( $p<0.0001)$, which in turn performed better than the novices $(p<0.0001)$.The expert group rated the overall realism of the simulator at 5.2, Intermediate group at 5.4 and the Novice group at 5.26 on a seven-point Likert scale. No statistically significant differences were observed between the group mean scores.

Conclusion Through this study we have demonstrated that our Porcine-Resin thorax model was able to discriminate between different levels of expertise (construct validity) in seldinger chest drain insertion. All the three groups have agreed that this offers a realistic experience in chest drain insertion training for residents (face validity) and in addition the experts believe that this model can also be used competency assessments.

\begin{tabular}{lllll}
\hline Group & N & Mean score & SD & Cl (95\%) \\
\hline Novice $<5$ procedures & 30 & 11.3 & 4.54 & 9.6 to 12.9 \\
Intermediate 5 to 25 & 30 & 19.3 & 4.5 & 17.9 to 21.8 \\
Expert $>$ 25 procedures & 22 & 33.95 & 7.27 & 30.5 to 37.3 \\
\hline
\end{tabular}

\section{REFERENCE}

1. Gallagher AG, Ritter EM, Satava RM. Fundamental principles of validation, and reliability: rigorous science for the assessment of surgical education and training. Surg Endosc 2003:17:1525-9. 